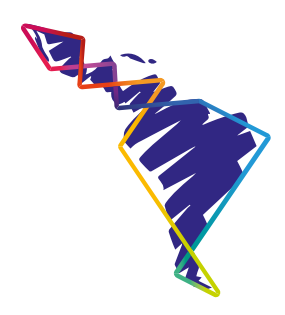

\title{
Dignidad humana: una mirada desde un enfoque filosófico
}

\author{
Human dignity: a view from a \\ philosophical approach
}

\section{Dignidade humana: uma visão de uma abordagem filosófica}

Alcira Noemí Samayoa Monroy

\begin{abstract}
Resumen
La dignidad de la persona constituye el fundamento vital de la idea de los derechos humanos, y aunque ha sido comunicado y continúa difundiéndose en nuestro tiempo, no pasa de ser un ideal en todos los países. Por lo tanto, el propósito de este artículo es reflexionar críticamente el valor de dignidad humana, desde un enfoque filosófico, ganando claridad al respecto, según el aporte de algunos pensadores como Aristóteles, Immanuel Kant, Martin Heidegger, Hannah Arendt, entre otros. Se parte de las categorizaciones pluridisciplinares y pluridimensionales, con las cuales se vincula el concepto de dignidad humana para su conformación, que nos lleva a la comprensión de este como el valor interno de la propia persona, por el hecho de serlo. Se incorporan, también, los avances notables respecto a la dignidad, con base una transición entre la edad moderna y contemporánea, como resultado de lo que el propio ser humano ha sido capaz de realizar. De tal manera, se precisa su consideración, porque actualmente la sociedad atraviesa por una decadencia de apreciación hacia la propia dignidad humana; conductas indeseables, específicamente en la sociedad guatemalteca, revelan que la persona se desvaloriza, evitando, incluso, que se le dé el honor debido como alguien individual y social.
\end{abstract}

Palabras clave: persona; dignidad humana; derechos humanos; ética; valores.

\section{Abstract}

The dignity of the person constitutes the vital foundation of the idea of human rights, and although it has been communicated and continues to diffuse in our time, it is still an ideal in all countries. Therefore, the purpose of this article is to critically reflect on the value of human dignity, from

1 Licenciada en Administración de Empresas, con estudios de Maestría en Filosofía. Docente titular del Centro Universitario de Oriente-, CUNORI, Universidad de San Carlos de Guatemala, Guatemala. ORCID: https://orcid.org/0000-0002-3029-966X 
a philosophical approach, gaining clarity in this regard, according to the contribution of some thinkers such as Aristotle, Immanuel Kant, Martin Heidegger, Hannah Arendt, among others. It starts from the multidisciplinary and multidimensional categorizations, with which the concept of human dignity is associated for its conformation, which leads us to understand it as the internal value of the person, due to the fact of being a person. Notable advances with respect to dignity are also incorporated, based on a transition between the modern and contemporary ages, as a result of what the human being himself has been able to accomplish. In this way, its consideration is required, because currently society is going through a decline in appreciation of its own human dignity; undesirable behaviors, specifically in Guatemalan society, reveal that the person devalues himself, even preventing himself from being given the honor due as an individual and social person.

Keywords: Person; Human dignity; Human rights; Ethics and values.

\section{Resumo}

A dignidade da pessoa constitui o fundamento vital da ideia dos direitos humanos e, embora tenha sido comunicada e difundida em nosso tempo, ainda é um ideal em todos os países. Portanto, o objetivo deste artigo é refletir criticamente sobre o valor da dignidade humana, a partir de uma abordagem filosófica, ganhando clareza a esse respeito, conforme a contribuição de alguns pensadores como Aristóteles, Immanuel Kant, Martin Heidegger, Hannah Arendt, entre outros. Parte-se das categorizações multidisciplinares e multidimensionais, às quais se vincula o conceito de dignidade humana para a sua conformação, o que nos leva a entendê-la como o valor interno da pessoa, pelo fato de ser. Também se incorporam avanços notáveis no que diz respeito à dignidade, a partir de uma transição entre as idades moderna e contemporânea, a partir do que o próprio ser humano tem sido capaz de fazer. Dessa forma, sua consideração se faz necessária, pois atualmente a sociedade vive um declínio na valorização da própria dignidade humana; Comportamentos indesejáveis, especificamente na sociedade guatemalteca, revelam que a pessoa é desvalorizada, impedindo até de receber a homenagem que lhe é devida como pessoa individual e social.

Palavras-chave: Pessoa; Dignidade humana; Direitos humanos; Ética e valores.

\section{Introducción}

Hace apenas medio siglo empezábamos a escuchar un énfasis hacia la dignidad del ser humano, como fruto de la reflexión de las atrocidades cometidas durante la Segunda Guerra Mundial, rechazando, así, todas aquellas barbaries cometidas hacia la misma humanidad en las guerras mundiales.

Todo proyecto de vida del ser humano debe contemplar un desarrollo integral basado en la idea de que él es un fin y jamás un medio. Para Marina y De la Válgoma (2000), la dignidad humana aparece, pues, como una seña de identidad de 
la persona, dotada de inteligencia y libertad, como ser moral. La idea de dignidad resulta tan atractiva, que se manifiesta en la actualidad como uno de los "ganchos" transcendentales del discurso moral de la humanidad, que ha encontrado su mejor definición operativa y su concreción más palmaria en el concepto de derechos humanos (Marín, 2007).

Este ensayo no pretende agotar el tema, únicamente su interés es presentar reflexiones críticas en torno a la problemática; se desarrolla en los siguientes momentos: la dignidad humana como categoría pluridisciplinar y pluridimensional, dignidad humana durante el siglo moderno y contemporáneo, dignidad humana, fuente de derechos humanos, la persona humana es cocreación, el justo medio en Aristóteles y dignidad humana en Guatemala.

\section{La dignidad humana como categoría pluridisciplinar y pluridimensional}

Considerando la primera categoría para la caracterización y configuración de la dignidad humana, es necesario comprender que se impone en su interrelación con varias disciplinas: la filosofía, antropología, política y derecho. Sin embargo, en este ensayo nos apoyaremos únicamente en la ética y el derecho.

Específicamente la ética, se interesa por la dignidad humana, pues la propia persona es fuente de derechos y deberes. En ella se asienta el hecho moral; es sujeto de los actos morales, la que valora y va descubriendo en sí misma las normas morales, la que experimenta el hecho primigenio de la conciencia moral. Y es finalmente la persona humana la que, apoyándose en sus vivencias y teniendo en cuenta todas sus relaciones, es capaz no solo de captar el hecho y el deber moral, sino también de indagar su objetividad y fundamento.

En cuanto al derecho, la idea de dignidad aparece en los textos jurídicos indisolublemente ligada a la Declaración Universal de Derechos Humanos, en 1948. Cada individuo independientemente de su condición social, cultural y económica, tiene derechos inalienables y dignidad, por tanto, en todo momento y lugar deben ser garantizados. La dignidad humana es la causa de que se reconozcan los derechos en sí, es su justificación misma.

Ahora bien, las disciplinas mencionadas anteriormente sirven para la conformación del concepto de dignidad humana, entendido como el valor interno de la persona, por el hecho de ser persona, en razón de su ser. Sin embargo, no basta relacionar el concepto de dignidad humana con disciplinas afines para la comprensión de la persona y su ser. 
Es necesario conocer su extensión, a través de lo que Ruiz citado en Marín (2007), llama categoría pluridimensional de la dignidad humana. Según él, la persona posee una dimensión religiosa, ontológica, ética y social. La primera dimensión (...) concibe a la persona a imagen y semejanza de Dios, con el cristianismo en escena la dignidad se fundamenta en un vínculo con la divinidad. Mientras que en la segunda dimensión se indica que la persona está dotada de inteligencia racional, con conciencia de sí mismo y de su superioridad en el orden del mundo. Por otro lado, la tercera dimensión establece que la persona es poseedora de un sentido de autonomía moral, como esencial función de la conciencia valorativa ante cualquier norma y ante cualquier modelo de conducta. Y finalmente, la cuarta dimensión (recogida por el Diccionario de la Real Academia de la Lengua Española) define a la dignidad humana como la forma de comportamiento de la persona presidida por su gravedad y decoro. (p. 2)

\section{La dignidad humana durante el siglo moderno y contemporáneo}

Contextualizando el tema que nos interesa, encontramos que durante la época antigua y medieval, muy poco se interesaron por elevar la dignidad de la persona humana a un orden superior, con respecto al de los demás seres en el cosmos. Para Verdross (1983), filósofos clásicos como los sofistas, seguidos por Sócrates, Platón y Aristóteles, plantearon la existencia de la naturaleza y concibieron así la dignidad de la persona. Sus ideas posteriormente fueron recogidas por Cicerón (...), quien claramente fundamenta la dignidad en la naturaleza humana.

Sin embargo, avances notables al respecto los encontramos a partir de una transición entre la edad moderna y contemporánea, como resultado de lo que el propio ser humano ha sido capaz de realizar. Durante la modernidad resalta la configuración de la persona convertida en el centro del mundo. Con ello, se obtienen aportaciones relevantes a la formación del concepto de dignidad humana en pensadores procedentes de la corriente humanista, en sus dos versiones, cristiana y laica.

Se citan las influencias de Giordano Bruno o Pico de la Mirandola en su célebre discurso "De dignitate hominis" (1486), en el cual aparece este nuevo punto de vista sobre el valor moral de la persona y su lugar en el mundo, cuestionando ¿qué razones hacen de la persona el ser más digno de admiración? Este texto tuvo un gran impacto en la cultura europea y su repercusión fue capaz de llegar a la obra de J. L. Vives, quien, en "Fabula de homine" (1518), recrearía literariamente el tema de la dignidad humana (Marín, 2007).

Tanto en Vives como en Pico la dignidad estriba en esa versatilidad, libertad o capacidad humana de llegar a lo más alto, porque la persona nace digna y todos los 
seres humanos son igualmente dignos. También, se suele mencionar la influencia del iusnaturalismo racionalista de los siglos XVII y XVIII, sobre todo de la doctrina de Puffendorf relativa a los entes morales "entia moralia" y las diferencias establecidas por dicho autor respecto a los entes físicos "entia physica".

Pero no es sino hasta en la ética kantiana, expresada en algunos textos de la "Fundamentación de la metafisica de las costumbres", que se logra una expresión más clara de la idea de la dignidad como categoría ética, vinculada a la dimensión moral de la persona. A ella se deben también los primeros intentos de basar los derechos humanos en la noción de dignidad.

Kant consideró la autonomía personal como el principal rasgo humano y, en tal contexto, nos habla de la dignidad de un ser racional que no obedece a otra ley que aquella que se da a sí mismo. Así pues, la moralidad y la humanidad, en cuanto a que la segunda es capaz de la primera, son lo único que tiene dignidad. "El hombre, y en general todo ser racional, existe como fin en sí mismo, no sólo como un medio para ser utilizado discrecionalmente por esta o aquella voluntad [tanto en acciones orientadas hacia sí mismo como hacia otros] el hombre es un fin" (Aramayo, s. f., p. 137).

Con el aporte de Kant, encontramos que la persona tiene dignidad, no precio, pues todos los objetos irracionales tienen un valor (material/uso) condicionado, relativo como medio, mientras que los seres racionales están libres de ello; por lo tanto, "reciben el nombre de personas y su propia naturaleza los destaca como fines en sí mismos como algo que no cabe ser utilizado simplemente como medio, y restringe así cualquier arbitrio (al constituir un objeto de respeto)" (Aramayo, s. f., p. 138).

Siendo así, Kant expresa este principio de dignidad e inviolabilidad de la persona conectada con el imperativo práctico: "Obra de tal modo que uses a la humanidad, tanto en tu persona como en la persona de cualquier otro, siempre al mismo tiempo como fin y nunca simplemente como medio" (Aramayo, s. f., p. 139).

En otras palabras, todo proyecto de vida de la humanidad, que cumple un desarrollo integral cimentado en la idea de que él es un fin y jamás un medio (instrumento), comienza con la educación. Se construye desde la formación e inagotablemente se continúa con ella porque se aprende y se vive hasta el último momento de nuestra existencia. La educación ofrece al ser humano un horizonte de posibilidades infinitas, las cuales solo deben apuntar hacia el bien. De tal modo, la dignidad de la persona comprende una manera determinada de vivir una vida humana. Es un modelo del pensar, del vivir y del hacer. 


\section{La dignidad humana, fuente de derechos humanos}

Cabe mencionar que el término de dignidad humana es de reciente incorporación en la literatura jurídica. Países como Estados Unidos y Francia, a finales del siglo XVIII, en sus declaraciones no hacían referencia a la dignidad como tal, sino únicamente a nociones de libertad, igualdad, propiedad e incluso, si al caso incluían el tema de felicidad. Pero del siglo XVIII hasta mediados del XX, los hechos perpetrados producto de las guerras mundiales generaron mucho espanto.

Filosóficamente hablando, el siglo XX, se convirtió en asombro ante un ser humano capaz de lo más sublime y lo más perverso, de lo más hermoso y lo más siniestro. Se llega a repensar en la condición humana en sí, ante una humanidad desequilibrada, desprotegida, desvalorizada; hombres y mujeres aspiran a tener las mismas aperturas, en cuanto a oportunidades educativas, sociales, religiosas, laborales, así como a exigir un mundo más justo y pacificador.

Los derechos humanos irrumpen en ese contexto, logran un espacio y un redireccionamiento de una humanidad caracterizada por el etnocentrismo imperante; realizan avances en materia de pacificación y valoración de la persona, independientemente de su color, raza, etnia, sexo, clase, casta, creencia religiosa, edad u orientación sexual, como expresan en su contenido de declaración con fecha de 1948. Es así como el concepto y realce de la dignidad humana pasó a incorporarse a los textos jurídicos, en el contexto de internacionalización de los derechos humanos, tras la Segunda Guerra Mundial.

La dignidad humana, es el valor fundador de todos los derechos humanos; constituye el fundamento incuestionable de la idea de estos, aunque existen otros valores fundadores, como libertad, igualdad, solidaridad, seguridad o paz, y la dignidad humana se sitúa a priori de estos, como su especie ontológica, como el núcleo fundamental de la idea de derechos humanos (Asamblea General de la ONU, 1948).

Según lo dicho, conviene mencionar lo que en la propia Declaración Universal se expresa, pues aún no se ha puesto fin a los abusos perpetrados en contra de los propios derechos humanos, pero sí innumerables personas han logrado una mayor libertad previniendo infracciones, logrando independencia y autonomía. Se ha podido garantizar a muchos, aunque no a todos, libertad ante la tortura, eximirlos del encarcelamiento injustificado, de la ejecución sumaria, desaparición forzada, persecución y discriminación injusta, así como conducirlos al acceso equitativo a la educación, oportunidades económicas, recursos adecuados y atención sanitaria (Asamblea General de la ONU, 1948). 
Ahora bien, aunque la acepción de dignidad humana ha sido comunicada y continúa, en nuestro tiempo, difundiéndose en el mundo, no pasa de ser un ideal en todos los países. Actualmente, la sociedad misma atraviesa por una decadencia de apreciación hacia la propia dignidad humana; conductas indeseables en ese ente social revelan que el propio individuo se desvaloriza, por lo tanto, tampoco permiten que se le dé el honor debido como persona individual y social.

La sociedad ha olvidado que una de sus atribuciones fundamentales es garantizar su existencia, la salvaguarda de todos los bienes en general y la convivencia entre los individuos. Para ello, requiere que la persona ordene y regule sus actividades, actos, funciones, relaciones en general con el otro y su desempeño.

El propio individuo en su desenvolvimiento social olvida o no quiere comprender que quienes le rodean son poseedores de honor; por ende, merecen respeto. $Y$ es que todas las personas somos poseedoras de derechos y deberes, pero, ¿qué evidenciamos al respecto? Ha sido una constante que los individuos apelen más a los primeros, dejando de lado los segundos, allí vemos pisoteada la dignidad humana que apela a entregar el bien moral al otro.

Se abusa de la persona, de su dignidad, cuando se ignora que tiene dignidad un hombre prominente como aquél que se encuentra privado de libertad por haber cometido un asesinato, homicidio, violación o robo por citar algunas faltas. $Y$ es que se ha olvidado, incluso, que es en el propio ser en el que se encuentra enraizada la dignidad humana, la persona vale por lo que es; ella misma debe cuidar su dignidad. Toda la humanidad es portadora de dicha cualidad, pues en esta se encierra la creación más privilegiada sobre toda la naturaleza, al ser poseedora de una dimensión racional y moral, que la facultan para tomar decisiones en cuanto a su voluntad.

Es así como, independientemente de sus logros y fracasos, de la posición social o económica, de sus rasgos físicos y capacidades mentales, tanto el hombre como la mujer, son merecedores de honor, porque tienen un común denominador que los califica como personas.

\section{La persona humana es cocreación}

La persona humana es privilegiada no solo por lo citado anteriormente, sino porque cuestiona hasta su realidad personal a través del entendimiento, su capacidad de decisión y su responsabilidad, que son parte de su dignidad. Vale la pena mencionar que, es gracias a la apertura del humano (entiéndase inteligencia y libertad), se considera como el único ser que se pregunta por sí mismo; más aún, se ve como 
impelido a interrogarse acerca de su existencia, ya que advierte que su ser no es un objeto hecho como un mineral, ni un mero viviente, como un pez o un pájaro, a quienes sus instintos van haciendo; sino que es un existente, es decir, alguien que camina hacia el porvenir, llevando a cuestas el peso del pasado y labrándose un presente.

Heidegger plantea un reto en cuanto al lugar que ocupa el ser en el mundo. No está aislado, sino que merece respeto, pero a la vez este valor debe darse en la cocreación que realiza en el mundo, porque la persona es un ser que se va haciendo, rodeado de otros objetos útiles, especialmente de otros seres personales a los que el filósofo llama Mitdasein. Ser persona es ser en relación, no sería correcto decir que la persona humana primero es y luego se relaciona, sino se debe decir, que como persona, existe relacionándose.

La idea previa se ha formulado también diciendo que la persona es un ser social, pero entendiendo esta afirmaci6n en sentido fuerte, es decir, es social no solamente por necesidad, como era considerado por Aristóteles, sino que lo es constitucionalmente (Aragó, 1997).

El humano es un ser con los demás y para los demás; en ello radica que la persona misma aplique, en el desenvolvimiento de sus relaciones interpersonales y sociales, una configuración de adaptación y personalización que la lleve a procurar el bien. Los vínculos desarrollados por personas, independientemente de la sociedad a la cual pertenezcan o de la cultura en la cual se manejan y se proyectan, no son un ligamen instrumental. La dignidad humana no contempla relaciones de ese tipo; el otro no es para mí un objeto, no es una relación de oposición (amo-esclavo), sino de reciprocidad, no es un nexo de dependencia, sino de encuentro (Lévinas, citado en Aragó, 1997).

En dicho encuentro, ya hay de por sí una implicación de intercambio, de intentar colocarme en el lugar del otro y verlo similar a mí, atendiéndolo como la persona que merece honor y respeto, pues poseemos una humanidad compartida. En esta última, el lenguaje, más que un constructo social y comprendido como señales y signos, ayuda a que como personas desarrollemos una realidad dialógica, con la cual podamos conocer y valorar a nuestros semejantes por lo que realmente son, no por lo que poseen y por lo que se puede obtener de ellos.

\section{El justo medio en Aristóteles}

Todas las sociedades se esfuerzan, por diversos medios, en transmitir a las nuevas generaciones los conocimientos, valores, hábitos, costumbres y técnicas que han 
conquistado desde el fondo del pasado hasta su propio presente. Transmisiones de ese tipo se han practicado desde tiempos muy remotos, mediante los diversos modos de comunicación o por las prácticas compartidas con quienes tienen amplia experiencia en ellas.

Por tal razón, como lo expresa Rojas (2010): “no es casualidad que los filósofos se detuvieran al estudio de principios epistemológicos, lógicos, éticos y estéticos de la actividad educativa de los seres humanos... Aristóteles evidenció un interés en la comunicación de principios éticos... como parte esencial de la vida ciudadana" (p. 26).

El postulado aristotélico en la Ética a Nicómaco gira en torno a la capacidad personal para poseer las héxis o virtudes, siendo estas superiores a la racionalidad, porque la virtud es la que perfecciona a la persona. El filósofo establece que "una virtud moral es una disposición afianzada de elegir el justo medio en las obras y los sentimientos...esta disposición se determina según un principio recto o siguiendo la pauta de los hombres que poseen sabiduría de vivir" (Aristóteles, 1946, p. 69).

Entonces, a la virtud Aristóteles le estableció un carácter de fin; es superior, por encima del ejercicio de nuestra razón. Este ejercitar de nuestra razón debe hacerse para la adquisición de las virtudes y, desde la adquisición de las virtudes, el ejercicio racional y práctico se perfecciona. Las virtudes no existen en nosotros por la sola acción de la naturaleza, ni tampoco contra las leyes de esta.

Las virtudes consisten en una disposición para obrar, elegir o tener una actitud determinada, según las situaciones que se presenten; tal disposición puede tenerse aun en los momentos cuando no es preciso actuar, elegir ni sentir la actitud, con tal de que se mantenga la posibilidad de reaccionar, de acuerdo con como haya llegado el momento o al presentarse la circunstancia. Las virtudes solo se conquistan mediante la constante repetición de actos de justicia, templanza, bondad, entre otros.

Es así como la virtud será la manera de ser moral que hace a la persona buena, de bien y gracias a la cual sabrá realizar la obra que le es propia, porque "la razón es lo que nos permite poseer los fines; pero lo que nos permite mejorar en cuanto que tales, o sea, en cuanto que somos lo que somos [personas]... eso se llama virtud" (Polo, 2011, p. 23).

De tal manera, la virtud es un medio relacionado con la persona y el bien, aunque no todas las acciones son susceptibles de ella. Pasión, malevolencia, tendencia a regocijarse del mal del otro, imprudencia, envidia, adulterio, robo, asesinato son ejemplos claros de ello. 


\section{La dignidad humana en Guatemala}

Guatemala es un territorio donde, según el reporte de diciembre del 2018, se estimó una población total de 14,901,286 personas, de las cuales 7,223,096 son hombres y $7,678,190$, mujeres ${ }^{2}$, con una pobreza general total de $59.3 \%$, al 2014 , y una pobreza nacional extrema de $23.4 \%{ }^{3}$. Por los datos descritos, la nación es considerada una de las que poseen sistemas administrativos precarios y, por lo tanto, muchos se han atrevido a llamarle un país en vías de desarrollo. Actualmente, tenemos una población considerable que se hace sentir en una sociedad decadente, por la falta de axiología en las personas que agonizan día tras día.

La referencia de la dignidad de la persona se encuentra en la Constitución Política de la República de Guatemala (2002). En su título I, aparece como norma de partida, regulando derechos y deberes, concediendo, en su capítulo único, el lugar privilegiado a la persona humana. Merece la pena citar el artículo $1 .^{\circ}$ porque señala: "Protección a la persona; el Estado de Guatemala se organiza para proteger a la persona y a la familia; su fin supremo es la realización del bien común. Y siguiendo, el artículo 2. ${ }^{\circ}$ establece "Los deberes del Estado; es deber del Estado garantizarles a los habitantes de la República la vida, la libertad, la justicia, la seguridad, la paz y el desarrollo integral de la persona".

Por lo tanto, apoyados en dichos artículos y abordando uno posterior, el 44 (señala los derechos inherentes a la persona humana ${ }^{4}$ ), puede decirse que la dignidad humana es el fundamento de la legitimación del orden político en el pueblo guatemalteco, del cual emergen todos los derechos y valores que deben evidenciarse. Tales derechos parecieran estar libres de toda garantía, pues la misma dignidad ha sido violentada porque el Estado no se hace notar en el papel de agente moralizador que le corresponde.

La dignidad de la persona implica reconocer al otro como otro yo, en las relaciones interpersonales; asimismo, atañe especialmente al Estado reconocer, garantizar y promover tanto esta dignidad como los derechos humanos, removiendo los obstáculos que se oponen a ello.

Necesario es reconocer que incluso el Índice de Desarrollo Humano (IDH) fue creado para hacer hincapié en que las oportunidades de las personas debería ser

2 Datos proporcionados por la página electrónica del Instituto Nacional de Estadística Guatemala (INE), a través de los principales resultados del censo 2018.

3 Programa de las Naciones Unidas para el Desarrollo. Sostenibilidad y equidad: Un mejor futuro para todos (2011). Recuperado de http://hdr.undp.org/sites/default/files/hdr_2011_es_summary.pdf.

4 Los derechos y garantías que otorga la Constitución no excluyen otros que, aunque no figuren expresamente en ella, son inherentes a la persona humana. 
el criterio más importante para evaluar los resultados en materia de desarrollo, teniendo como sustento tres dimensiones básicas, a saber: disfrute de una vida larga y saludable, acceso a educación y nivel de vida digno. Según la definición del Programa de las Naciones Unidas para el Desarrollo en Guatemala (PNUD), el desarrollo humano y los derechos humanos se reafirman mutuamente, ayudando a garantizar el bienestar y la dignidad de todas las personas, forjando el respeto propio y el de los demás.

En Guatemala, desde 1998, se han publicado diez informes nacionales de desarrollo humano, los cuales han tratado diversas perspectivas de este. Específicamente, el informe del 2011/2012 examinó la situación de las juventudes guatemaltecas, alrededor de un planteamiento sobre la oportunidad para el desarrollo humano que estas representan. Dicho informe narra que las condiciones de vida en Guatemala son muy riesgosas y difíciles para muchos jóvenes, mujeres y hombres, debido a que "las fuerzas que mueven la vida social lo hacen de manera contradictoria (...) incluyen a pocos y excluyen a las mayorías (p. 11)"5.

Por ello, la juventud guatemalteca encuentra grandes dificultades para vivir dignamente. Las condiciones para disfrutar de una vida íntegra son pocas y mal distribuidas, repercuten directamente en el desarrollo humano de los jóvenes y en las posibilidades de tener tanto capacidades como fortalezas para forjar y vivir lo que ellos desean.

Vale la pena preguntarnos, siete años después del informe en mención, ¿qué evidencia nuestra sociedad guatemalteca? ¿Ha mejorado la condición de vida social? ¿Qué acciones se han implementado para promover el desarrollo humano? A diario nos encontramos saturados con información, por los medios de comunicación, sobre actos violentos cometidos en contra de niños, jóvenes y adultos, de todo tipo. ¿Qué sucede con la dignidad humana en Guatemala? ¿La hemos olvidado? ¿Ha sido poco difundido el hecho de que como seres humanos merecemos respeto? $\mathrm{O}$, ¿simplemente es un tema que no interesa? Pero, ¿por qué algunas personas intentan hacer eco sobre una defensa necesaria de dignidad humana en comunidades, pueblos, aldeas y caseríos de grupos de habitantes?

Probablemente la respuesta a la última pregunta se encuentra en la preocupación sentida ante un comportamiento inmoral evidenciado por la propia sociedad guatemalteca. La dignidad humana es pisoteada cuando se cometen violaciones,

5 "Las situaciones y los factores de riesgo social operan en un medio calificado por la pobreza múltiple, las desigualdades sociales, una vida social degradada por la violencia y un Estado débil” (Informe 2011/2012, Programa de las Naciones Unidas para el Desarrollo en Guatemala, p.11). 
asesinatos, masacres, desmembramientos, privaciones de libertad; pues se ha olvidado hacer de aquella un valor cotidiano del cual se desprenden todos los demás.

La poca practicidad de los derechos humanos nos priva como sociedad guatemalteca y nos coloca en desventaja en un presente y un futuro prósperos; de esta manera, nos impide salir adelante. La dignidad humana es una privación social instalada en la vida diaria de nuestros habitantes, ella misma debe experimentarse de modo que remita a la presencia de otro.

Debemos reconocer que los propios derechos humanos fueron concebidos para una experiencia moral con todos los que nos rodean y con aquellos que convivimos diariamente, es lo que la propia ética $\operatorname{dicta}^{6}$. La interrelación en la cual probablemente experimentemos afrentas que afectan nuestro estado y coloca en evidencia nuestro comportamiento con dignidad, asumiendo la comprensión hacia el otro, actuando correctamente. Si por el contrario, lo que evidenciamos son reacciones ante la situación que nos envuelve y no respetamos ni comprendemos al otro, seguramente terminaremos ocasionando un daño, pisoteando a nuestros semejantes (la dignidad humana).

Desde esta perspectiva, el mal en la sociedad es producto de las propias actitudes del hombre. Hannah Arendt acuñó la idea de la banalidad del mal para enfatizar que este no precisa de monstruos, sino de seres humanos irreflexivos que siguen ciertos libretos sin cuestionarlos. Es así como la moralidad se ve violentada no solo por lo que hacemos, sino también por lo que dejamos de hacer (Rodríguez, 2017).

La familia, la escuela, la Iglesia, el Estado y la sociedad civil son el canal a través del cual la moral es introyectada en el individuo, para lograr su mejor desempeño y participación en la sociedad. Son el conducto por medio del que la sociedad busca garantizar su armonía dentro de ciertos criterios que norman, moralmente, la conducta del individuo (Ibarra, 1998), a quien probablemente está faltando a su responsabilidad.

No se puede concebir a la persona sin sociedad, pues, en realidad, ninguna persona se halla completamente aislada. Siempre y en todo lugar es integrante de una familia, mantiene relaciones con sus semejantes, forma círculos. La persona es, pues, eminentemente social. Vive en sociedad y es en ella como constituye su contorno vivo, su ambiente social. Precisamente es el contenido social lo que hace que un individuo sea una persona. Desde cualquier punto de vista que se analice la conciencia humana, siempre encontrará en ella un contenido social, porque la

6 Tomado del artículo publicado por elPeriódico, Guatemala: "La dignidad como valor cotidiano", de Rodríguez, J., el 22 de enero de 2017.

$12 \begin{aligned} & \text { Revista Latinoamericana de Derechos Humanos } \\ & \text { Volumen 32 (1), I Semestre 2021 } \\ & \text { ISSN: 1659-4304 • EISSN: 2215-4221 }\end{aligned}$ 
persona en abstracto no existe. Todo humano es un ser concreto. Pertenece a una familia, un pueblo, una raza, una cultura, una nación, una época determinada y un grupo profesional.

Todos estos factores sociales moldean la personalidad por múltiples influencias, como la imitación, educación y sugestión. Hay, por tanto interacción de influencias recíprocas del individuo y de sus semejantes, que implican interferencias mutuas, puesto que la acción y la libertad personal de cada uno de los integrantes de la sociedad se ven limitadas y restringidas por las aspiraciones particulares de cada quien. Se trata de una interacción y una dependencia mutua entre el individuo y la sociedad. De ahí la necesidad de propender a que las relaciones entre las personas mantengan el respeto que merecen, la armonía, conciliando, hasta donde sea posible, los intereses de la sociedad en sí; recordando que el que cuida de sí mismo, cuida de su hermano.

Porras (1979) advierte que, si se quiere vivir bien con todo el mundo, se deben soportar los defectos de los demás y procurar no herir el amor propio de nadie. Cada individuo, en cuanto sujeto de conciencia y reflexión, con atributos característicos y diferenciales del ser humano, viene a ser un microcosmos de la sociedad en general y, en particular, de las comunidades de nosotros.

\section{Conclusión}

Más que como personas individuales, como seres humanos, la dignidad humana debe llevarnos a desarrollar la capacidad de generar un mundo nuevo, de empezar una vida y añadirle algo más a la realidad. El sufrimiento y la destrucción se han convertido en el patrimonio de la humanidad y, por qué no decir, de nuestro propio país. De allí la importancia de apreciar la vida humana y de tomar conciencia de la condición en la cual esta se encuentra.

Se debe estar consciente de que de las personas podemos esperar lo inesperado, siempre que se defienda lo que en nosotros hay de irreductible, nuestra propia autenticidad; va a depender del yo profundo frente a la experiencia de lo uno. Sin embargo, el hombre como persona humana debe marcar la historia, su historia, sin olvidar la intersubjetividad, pues ella nos conduce a colocarnos en el lugar del otro para conocerlo, comprenderlo y valorarlo.

Debemos considerar lo que la propia hermenéutica llama horizonte de sentido, tomando conciencia de que, dentro del mundo al cual pertenecemos, no estamos alejados, colocados en una nube neutra desde la cual podemos mirar lo que acontece desde afuera, siempre estamos dentro, somos seres de comunidad, aun cuando 
pertenecemos a diferentes tradiciones, costumbres, credos religiosos, posición económica, estatus social o racial, necesitamos aprender a valorar a nuestros semejantes y respetarlos.

Tenemos que aprender, hoy más que nunca, a escuchar al otro, a entrar en la posibilidad de eso que Tomás de Aquino llamaba sentido común. Es preciso saber que el mundo es común, pero que cada uno lo aprecia y comprende desde un lugar distinto, sin que renunciemos a esta comunidad humana que somos; debemos aplicar la dignidad humana como un valor cotidiano dentro de dicha comunidad. 


\section{Referencias}

Aragó, J. M. (1997). Ética y Valores. Guatemala: Universidad Rafael Landívar. Reimpresión de la segunda edición.

Aramayo, R. R. (s.f.). Immanuel Kant: Fundamentación para una metafísica de las costumbres. España: Alianza Editorial.

Aristóteles. (1969). La política. España: Editora Espasa-Calpe, S.A. Madrid.

Asamblea General de la ONU. (1948). Declaración Universal de los Derechos Humanos $(217$ [III] A). París. Recuperado de http:/www.un.org/en/universal-declaration-human-rights/.

Di Pego, A. (2010). Modernidad, filosofía y totalitarismo en Hannah Arendt. Revista de Filosofia, 13, 35-57.

Ibarra, C. (1998). Elementos fundamentales de ética. México: Primera Edición.

Instituto Nacional de Estadística Guatemala. (2019). Principales resultados censo 2018. Recuperado de https://www.censopoblacion.gt/cuantossomos

Marín, M. L. (2007). La dignidad humana, los Derechos Humanos y los Derechos Constitucionales. Revista de Bioética y Derecho, 9, 1-8.

Polo, L. (2011). Tres dimensiones de la antropología. Studia Poliana, (13), 15-29.

Porras, L. S. (1979). Ética profesional, relaciones humanas, relaciones públicas y laborales. Guatemala: Tercera Edición.

Programa de las Naciones Unidas para el Desarrollo. (2,011). Informe sobre desarrollo humano 2011, sostenibilidad y equidad: Un mejor futuro para todos. Estados Unidos.

Rodríguez, J. (22 de enero de 2017). "La dignidad como valor cotidiano". elPeriódico. Recuperado de https://elperiodico.com.gt/domingo/2017/01/22/ la-dignidad-como-valor-cotidiano/

Verdross, A. (1983). La filosofía del derecho del mundo occidental, visión panorámica de sus fundamentos y principales problemas. Ciudad Universitaria, 04510 México, D. F.: Universidad Nacional Autónoma de México. 
